the major tronds in the deviations of the masses and shapes of nuclei, from those predicted by a liquid drop formula, could be accounted for in a rough way on the basis of a semi-empirical expression with three parameters. These new formulæ should make possible a better assessment of the mass and energy balances in fission which, as diseussed at the meeting, are seriously wrong for uranium-235 and plutonium. 239 fission on the basis of the old mass formulx.

In the session on spallation, K. F. Chackett (Birmingham) interpreted his results from $(p, n)$ reactions on the basis of the optical model of the nucleus, and $\mathbf{N}$. Lefort (Paris) described proton reactions in terms of $\alpha$-particle structures in the nucleus. G. R. Martin (Durham) reported cross. sections for $\left(n,{ }^{3} \mathrm{He}\right)$ reactions, and for $(n, p n)$ processes; the latter seemed to agroo well with a direct interaction model', rather than with an evaporation mechanism. Again, the excitation functions of $(d, 2 n)$ reactions reported by $\mathrm{L}$. J. Gilly (Louvain) failed to agree with predictions of neutron evaporation from compound nuclei. In discussion the general view was expressed that for spallation phenomena the theoretical background is at present very inadequate.

Among the papers on radioactive decay some new isotopes were reported, notably radon-223 (halflife $39.8 \mathrm{~min}$.) and radon-224 (114.8 $\mathrm{min}$ ) by V. J. Robinson (Liverpool). A paper was given by J. Maly (Dubna) on a new method for the preparation of mondelevium by the bombardment of uranium with neon ions, and some details of the chemistry of this element were reported for the first time. Interesting accounts were given of activation processes (M. Lindner, Livermore), and of the production of transuranic elements (J. D. Knight, Los Alamos), in underground nuclear explosions.

The session on chemical effects was restricted to studies in which different nuclear events could be compared. A. G. Maddock (Cambridge) compared the condition of chromium-51 formod by the $(n, \gamma)$ process on chromium-50, with its condition when formed by the $(n, 2 n)$ process on chromium-52 in solid potassium chromate. While no significance could be seen in the initial retention, the subsequent annealing of the material formed in the more highly energetic $(n, 2 n)$ procoss was shown to be slower than the annealing of that from the weaker $(n, \gamma)$ process. In subsequent papers by I. G. Campboll (Manchester), L. Lindner (Amsterdam), and G. E. Miller (Oxford), the importance of the annealing or recombination processes was again emphasized. In the discussion attention was directed to the pressure effects which may influence the 'rigidity' or 'softness' of crystal structures in solids, and 'cage' effects in liquids. F'our papers were given on the effects of fission recoil, and in discussion particular attention was given to the sputtering processes that occur whon fission fragments pass through surfaces.

In sessions on techniques consideration was given mainly to tho problems of flux monitoring. In particular the accurate measurement of roactor neutrons by cobalt activation was described by T. A. Eastwood (Chalk River, Canada) and of neutron spectra from cyclotron targets by A. H. W. Aten, jun. (Amsterdam). New methods for conducting fast chemical separations for measuring short-lived radionuclides were also doscribed. For example, (G. Herrmann (Mainz) showed that thin layers of fresh crystalline precipitates on filters retain a large fraction of their own and rolatod ions from solutions filtered rapidly through them. The most notable advance in recent years in radiochemical techniques for the analysis of mixtures of radioactive isotopes is the use of a mass separator in which the relative amounts of the activity on the different target areas where the different nuclides are deposited is moasured. P'apers by G. Andersson (CERN), and T. A. Eastwood, described this technique, and a third paper was given by H. Ewald (Munich) on the application of a similar technique to the mass separation of highly charged fission fragments during their formation. A refined method for the measurement, by mass spectrometry, of stable fragments (lithium-6 and lithium-7) formed in high-energy proton irradiations was described by E. Gradsztajn (Orsay).

The meoting concluded with deseriptions and comparisons from Livermore and Aldermaston of the computer programmes used in the large-scale analyses of radioactive decay data.
G. N. WaLton

\title{
FUTURE OF TEACHING MACHINES
}

$\mathrm{P}$ ROF. B. F. SKINNER, of the Department of Psychology, Harvard University, delivered an address on "The Future of Teaching Machines" on Oetober 19 in the University of Oxford, at the invitation of Prof. R. C. Oldfiold. Prof. Skinner began by commenting on the present state of confusion in this field, which is now barely eight years old. This confusion was partly dne to commorcial interost in producing programmed texts, partly to the enormous growth in the needs of education, with ever more students to be taught and ever more to teach them, and partly to the activities of 'gadgeteers' who delighted in inventing a variety of devices which could be referred to as 'teaching machines' but which wero not based on a knowledge of the learning process.

Though education is often considered a preparation for the real world, it is difficult to bring tho real world into the classroom; consequently, education has in practice mainly concerned itself with setting up verbal repertoires of one sort or another, teaching the student to speak a language, to perform mathematics, essentially a vorbal procedure, or to command the facts of a scionce. The first learning machines which had been developed in his department had similarly been directed to the development of verbal skills. They required the student to fill in a missing letter in a word, a word in a sentence, or a term in an equation; if right, the student moves on to a new frame; if wrong, he must try again. In this way he works through the programmo. Present-day programmes advance by very small steps, so that students make few errors and very little repetition is required. Though the material scoms very simple tho studonts move on to advanced technical material very rapidly. The students in his course at Harvard spent their first month using the machines in the "self-instruction room'. At the end of that period he could lecture to them secure in the knowledge that they had mastered the tochnical material necessary for the course.

Two effects of the uso of these machines were worthy of note. The first was the improvement in the pupils' motivation which they produced. In most 
schools children studied because they did not dare do otherwise; but children using the machines became absorbed in the work. He had visited an eighth-grade class in Roanoke engaged in studying a programme on algebra in an experiment by Dr. A. Calvin. Not a head was raised from a machine while he wandered through their classroom talking to their teacher. In Toronto an experiment came awry because the children would not restrict their studying to the prescribed hours but smuggled the programmed text (on English grammar) out of school for further study. The children became confident and interested; on returning to ordinary teaching methods they were alert and ready to offer comments. The second effect depended on the fact that the machine allowed each student to go at his own pace. It has been said that what would astonish Plato most to-day is that we attempt to teach two students at the same time. One result of teaching large numbers at the same rate is that the slow student cannot keep up and rationalizes his failure. Yet there is no evidence that the slow student cannot do first-class work if he is given the time to do it. In one experiment, by Dr. D. Cook, an 800-frame programme on chemistry was presented to a class whose intelligence quotients ranged between 100 and 140 . It was found that the least intelligent children took approximately twice as long to finish the programme as the brightest, but when tested at the end there was little difference in their achievement scores. Given enough time it appeared that the slow student could do as well as his swifter colleague.

The basic experimental research which had allowed the development of this new sort of educational technology was then discussed. This had relied not on statistical surveys but on the intensive study of individual organisms with a view to analysing the effective environmental factors and developing the ability to predict behaviour from a knowledge of the environment. It had been found that the contingencies of reinforcement had an extraordinary power to select and control behaviour. This was illustrated by a classroom experiment in which the class chose the behaviour, such as bowing, tracing a circle, or leaning over backwards, which they wished a pigeon to perform, and this was produced in a few minutes solely by governing the intermittent food reinforcement given it. At first the experimenter rewarded behaviour corresponding within liberal limits to that required; when the animal repeated this the reinforcement would be made conditional on a more exact correspondence to the prescribed behaviour. More complex reinforcement contingencies could not readily be produced by hand but required special apparatus. This set environments in which certain behaviours would develop. In one sense these devices were teaching machines.

One problem was whether learning could be produced if the animal never made an error; it had been shown experimentally that this was possible. In an experiment by Dr. H. Terrace the aim had been to train a pigeon to discriminate between a pattern of horizontal lines and one of vertical lines without ever having made the error of pecking at the vertical lines. Initially the animal was presented with a key in bright red illumination. It pecked at the key and was rewarded, and the illumination was simultaneously removed. When this sharp change has occurred the pigeon does not peck the key again at once. Before it can do so the key again becomes bright red, the pigeon pecks, and is again rewarded.
The intervals between illumination of the key can then be gradually increased without the pigeon ever pecking at the key when dark. The next stage was gradually to add a greenish tinge to the dark key, and decrease the brightness difference, until eventually the pigeon was discriminating perfuctly between a red and green of equal brightness. The horizontal lines were then superimposed on the reddened key and the vertical lines when it was green, and they were gradually made more salient while the colours were gradually 'vanished', until finally the desired discrimination was being made by an animal that had never made an error. This showed that trial and error was not essential for learning, and it produced a 'bonus': a pigeon trained in this way was completely neutral to the negative stimulus, it did not show the 'emotional' behaviour often found when an animal is confronted with a stimulus which it has frequently pecked without reward.

Some programmes have been produced in which the student makes errors and the programme then produces comments on them. But it seems this is not necessary; programmes can be devised in which very few errors need be made. Prof. Skinner's first attempt of this sort was made when his small daughter was given the task of learning a passage of poetry. He wrote it on the board and she read it through. She then left the room, he erased some letters, she returned and read it through again. After four or five readings there was nothing left on the board but she could still "read it through".

One of the most common criticisms of teaching machines was that they might be useful for rote learning, but that they could not teach a child to think. This was not the case. Actually in practice we did not usually teach thinking; students were presented with problems and we claimed credit for those who solved them. The others were left by the wayside. We most often taught verbally, and when we did not we tended to teach 'final products', for example, to teach driving in a motor-car or flying in a cockpit, real or simulated. If we analysed the process of thinking, and such achievements, we might find that there were basic skills necessary to them which could be taught one by one. A programme designed by Drs. Holland and Long to teach "inductive thinking' was described. Programmes had been developed for teaching a number of non-verbal skills, and some of the more important developments of the future might lie in this area. Prof. Skinner described a device intended to cultivate a sense of rhythm. This required the child to tap in unison with a presented rhythm. At first very approximate agreement was acceptable, but the limits were gradually decreased until skilled performances were produced. Even professional musicians tested with this apparatus showed unexpected defects, such as a tendency to be just ahead or just behind the presented rhythm, or, very commonly, a tendency to speed up if their performance was good. Another device was being used to teach 'tone-deaf' children to discriminate pitch. Beginning with coarse discriminations they were gradually brought to the point where they could discriminate tones or semi-tones. Without devices such as these it was scarcely possible to provide the differential contingencies of reinforcement which would 'shape' such types of non-verbal behaviour. Eventually we may hope to be able to teach all the basic skills constituting adaptation to the environment, and so to enable man fully to exploit all his potential skills. 